\title{
THE ESPE E-LEARNING WEBPORTAL: A GLOBAL TOOL FOR INSTRUCTION AND FORMATIVE ASSESSMENT OF PEDIATRIC ENDOCRINOLOGY
}

\author{
Stenvert L.S. Drop ${ }^{1}$, Laura Kranenburg ${ }^{2}$, Sam Reerds ${ }^{1}$, Kalinka Grijpink ${ }^{3}$, \\ Violeta Iotova ${ }^{4}$ \\ ${ }^{1}$ Division of Endocrinology, Department of Pediatrics, Sophia Children's Hospital/ \\ Erasmus MC, Rotterdam, the Netherlands \\ ${ }^{2}$ Department of Internal Medicine, Maasstad Ziekenhuis, Rotterdam, the Netherlands \\ ${ }^{3}$ Division Education and Student Support, Faculty EEMS, Delft University of Technology, \\ Delft, the Netherlands \\ ${ }^{4}$ Department of pediatric diseases and medical genetics, \\ Medical University of Varna, Bulgaria
}

\begin{abstract}
The ESPE e-learning portal (http://www.espe-elearning.org) aims at supporting the learning of cognitive objectives, competencies and skills at two levels: core (medical students) and advanced (fellow/postdoc). It provides a rich source of up-to-date information on various Pediatric Endocrinology topics. The ESPE elearning webportal offers a set of functionalities consisting of a general learning content (chapters, problem solving cases, self-tests, glossary, community) and the option to construct specific courses for an event (ESPE school) or organization: a client, university or institution. Moreover, a set of question types has been developed allowing scoring and assessment of competencies. The content is being expanded and includes chapters and/or cases on the topics of growth, puberty, DSD, calcium and bone, diabetes, hyperinsulinism, thyroidal disorders, adrenal disorders, dis-electrolytemia. Since the portal has been moved to its definite address the global use of the portal has increased: during the period September - December 2013 there were 1264 visits; during the period January-April 2014 there were 2393 visits. The availability of the portal for members and non-members of ESPE needs to be emphasized and needs to be made public widely. Moreover, relevant feedback from users should be translated by the editorial board to make practical improvements. As demonstrated during two courses held in Varna, Bulgaria the portal facilitates the combination of online learning and face-to-face instruction: blended learning. Finally, the next step in extending the impact of the e-learning portal is the further development of learning and competency assessment tools. Furthermore, in demonstrating its applicability at a global level, regional and cultural aspects should be fully recognized.
\end{abstract}

Address for correspondence:

Stenvert L.S. Drop, MD, PhD.

Division of Endocrinology, Department of Pediatrics Sophia Children's Hospital/Erasmus MC

PO Box 2060, 3000 DR, Rotterdam, the Netherlands

e-mail: s.l.s.drop@erasmusmc.nl

Received: May 20, 2014

Accepted: September 10, 2014

\section{INTRODUCTION}

In an effort to combine instruction and formative assessment in learning as well as CompetencyBased Medical Education (CBME), the European Society for Pediatric Endocrinology launched the initiative to develop an interactive e-learning portal for Pediatric Endocrinology (1). The ESPE e-learning portal (http://www.espe-elearning.org) provides a 
rich source of information for experts, fellows, residents and students. The portal is freely accessible for medical students and professionals through a simple login procedure. So far, many specialists worldwide have contributed to the portal. This has resulted in numerous chapters concisely describing physiology and pathophysiology and practical approaches to management and treatment.

In addition, real-life cases are given where the student/fellow is invited in a step-wise and interactive manner to solve the diagnostic and management problems. In addition, real-life cases are integrated so students may consider solutions for the diagnostic and management concerns in a step-wise and interactive manner.

The ESPE e-learning portal (http://www.espe-elearning.org) aims at supporting the learning of cognitive objectives, competencies and skills at two levels: core (medical students) and advanced (fellow/ postdoc).

Access is provided through an automated login procedure via password protection and is in principal global and unlimited.

Over the last years major emphasis and energy has been put into the technical consolidation of the portal. The portal has been moved recently to its definite address using the ILIAS system $(2,4)$.

Several small-scale pilot tests have been performed to test applicability and content by senior experts, fellows, residents and students. Overall, elearning was considered very effective compared to other learning methods, such as literature and textbooks. There was a remarkably strong wish for personalized feedback by students and fellows. Therefore a pilot test was performed testing the interaction between fellows and experts. The results suggest that personalized feedback is useful to train certain competencies. Especially 'Medical Expert', 'Health Advocate' and 'Scholar' seem suitable to train with personalized feedback questions, but also 'Communicator' and 'Professional' might also be suitable (5).

Here we present a summary of the current functionalities of the ESPE e-learning portal. In addition we present the global use of the portal during the period September 2013 through March 2014 and the first experiences with special courses.

\section{Authentication and Registration}

All users must login to access any e-learning content. The subsequent steps leading to registration are depicted in fig 1 . By default, all student/visitor accounts will be valid for a period of 6 months. After 6 months an account can be reactivated for another period with an account code.

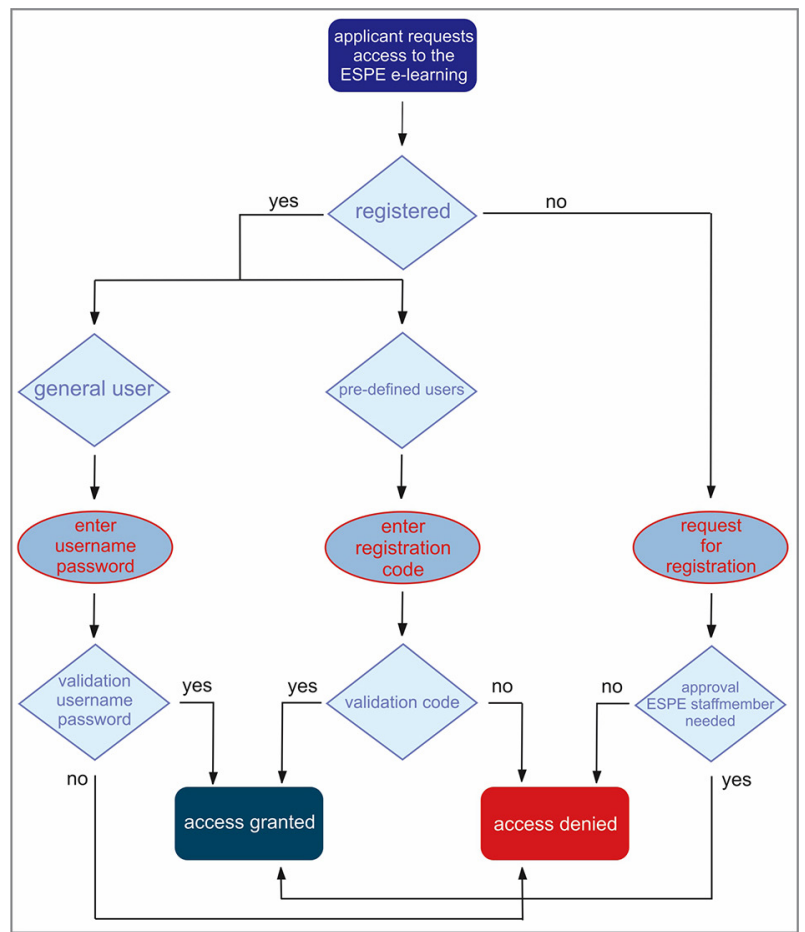

Fig 1. The authentication and registration process

1. A site administrator will create logins for staff users, i.e. the chief editor, content manager(s), content editor(s), content authors, and teachers.

2. A student/visitor can obtain a login by means of: a. Self-registration, requested through a registration-form on the login. Approval needed of the site administrator or an authorized staff user.

b. Self-registration with registration code. These pre-registered codes will grant an immediate access-approval.

c. Pre-registration (username and password) by a site administrator or staff user.

\section{Content generation}

The workflow involved in the generation of general content of the portal is given in fig 2 .

\section{Content Repository}

The ESPE e-learning portal offers two types of e-learning content: general learning content and specific courses provided for an event or organization. 


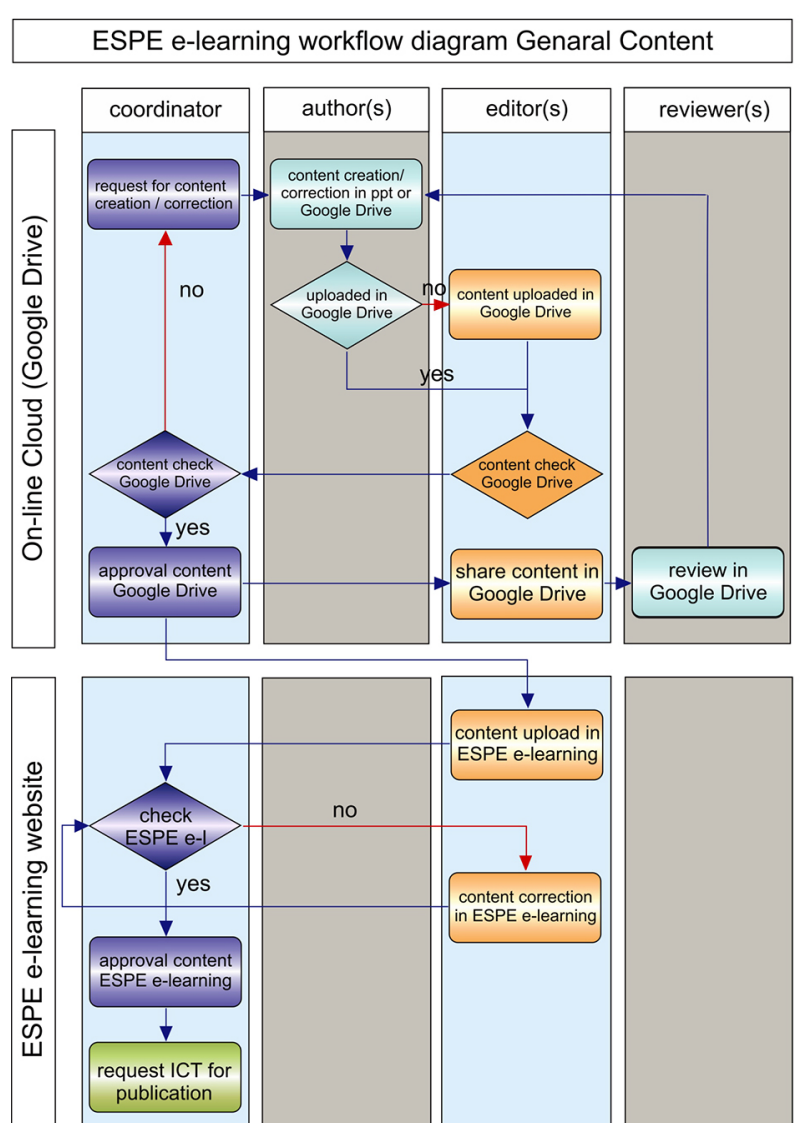

Fig. 2. Workflow of the generation of general content of the espe-elearning portal.

1. The coordinator request author(s) to create content: (part of) chapter or problem solving case.

2. The concept content (text and figures, diagrams, etc.) undergoes a first review by editor(s) and coordinator: proposal for additional art-work (animations).

3. The content may be reviewed by editor(s) and invited reviewers and is subsequently submitted to the author(s)

4. Following approval of the coordinator the definitive content is uploaded in the ESPE e-learning portal.

5. The content is checked by the coordinator and if necessary by the editor(s) and following final approval this final version is published on line

\section{General e-learning Content}

All registered users have access to all general elearning content on all available topics, e.g. Adrenal, Calcium, Diabetes, DSD, Growth, Hyperinsulinism, Puberty, Thyroid.

As shown in table 1, the general e-learning content consists of several Chapters, Cases, Formative Tests, Glossary, and Communities.

Formative assessment is implemented through various question types with direct feedback (see below). Formative Tests consist of question types that the portal evaluates automatically and can be done repeatedly.

\section{Courses Provided for an Event or Organisation}

For specific events, e.g. ESPE school or workshop, a course can be assembled by creating copies from a variety of chapters and cases of the uploaded e-learning content. Therefore it is possible to create a user-group-specific e-learning course for the client, e.g. university, hospital or society. A course is invisible for others except for the participants of the specified event or organization and users will have to login separately in order to join and to gain access to a course. Generally, it is limited for a period of time at the discretion of the organizer.

A Course consists of chapters and cases but in addition may contain exercises and/or tests.

An exercise is a problem solving case containing additional open questions inviting the student to communicate with the teacher who engages in direct formative feedback by email.

A test may consist of a set of (MC) questions and one or more problem solving cases. The student agrees to provide replies to questions which are

Table 1. Content of general espe-elearning portal (per 01-06-2014)

\begin{tabular}{|c|c|c|c|c|}
\hline Themes & $\begin{array}{l}\text { Chapters Published } \\
\text { (on line) }\end{array}$ & In progress & $\begin{array}{l}\text { Cases Published (on } \\
\text { line) }\end{array}$ & In prog-ress \\
\hline adrenal & & 1 & & 3 \\
\hline calcium/bone & 3 & 1 & 4 & \\
\hline diabetes & 1 & 1 & 1 & 2 \\
\hline DSD & 13 & & 7 & \\
\hline dyselectrolytemia & & 1 & & \\
\hline growth & 3 & 1 & 8 & 6 \\
\hline hyperinsulinism & 1 & & & 1 \\
\hline puberty & 1 & & 7 & 1 \\
\hline thyroid & & 2 & & 1 \\
\hline
\end{tabular}

Scripta Scientifica Medica, vol. 46, No 3, 2014, pp. 11-18

Copyright (๑) Medical University of Varna 
sealed and subsequently scored resulting in a pass/ fail summative test result.

\section{Question types in the ESPE-elearning portal}

Supported in general content, exercises and tests.

a. Single Choice: one answer can be chosen from several (4-5) predefined response options.

b. Multiple Choice: participants choose one or more among several predefined response options

c. Close: this question type consists of a text (including mark-up tags the gaps), featuring answers either in the form of text gaps or select gaps.

d. Numeric: with numeric questions students enter numeric values on their own. By means of an upper and lower limit, a corridor of correct answers is defined. Thus, it is a special example of a text gap.
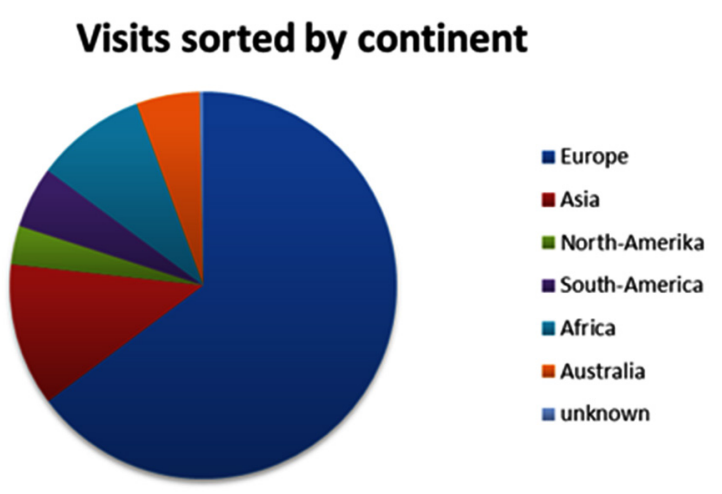

Fig 3. h. Imagemap: pictures featuring clickable areas (so called hotspots).

Supported in exercises and tests

i. Essay: An essay question is a short assignment that treats a topic from an author's personal point of view, often taking into account subjective experiences and personal reflections.

j. File upload: In addition to free-text questions, it is also possible to set open tasks that go beyond putting together texts, for example creating sketches, presentations or computer programs.

\section{Use of the portal}

Since the portal has been moved to its definite address the global use of the portal over the period from 01-09-2013 to 01-05-2014 shows a widely spread origin of its users, as shown in fig 3 and tables $2 \mathrm{a}, 2 \mathrm{~b}$.

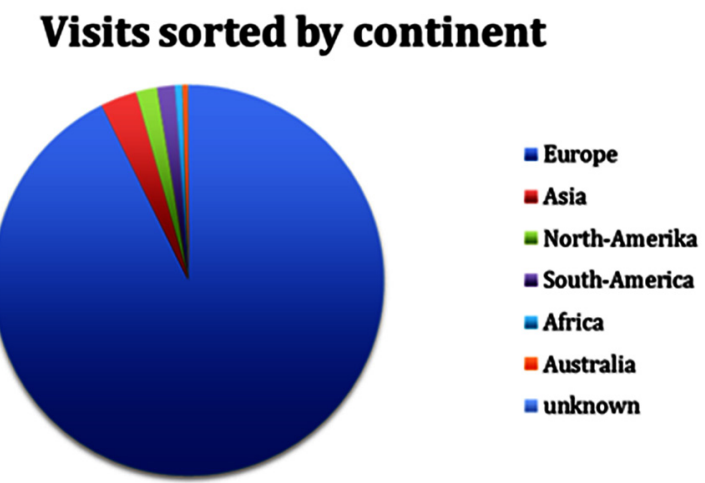

Visits of the portal sorted by continent. Fig 3a. In total during the period September through December 2013 there were 1264 visits: Europe819; Asia151; North-America 41; South-America65; Africa 117; Australia 67; unknown 4. Fig 3b. In total during the period January through April 2014 there were 2393 visits: Europe 2218; Asia 72; North-America 42;

South-America 35; Africa 15; Australia 11; unknown 1.

e. Text subset: with Text subset questions, students enter on their own a predefined number of terms which can be an arbitrary selection (subset) from a more comprehensive set of correct answers. Thus, it is a special example of a text gap.

f. Matching: students are matching pairs of predefined text and/or picture items ("terms" and "definitons"). Questions may be created in two variants: matching terms and definitions or terms and pictures.

g. Ordering: with Ordering Questions you predefine a number of pictures or terms, which have to be set into the correct succession by the students.
The average time that the portal is used is $12 \mathrm{~min}$ utes. However, in Kenya and Nigeria the visiting time is substantially higher as the portal is actively used by students of the PETCA - Nairobi (Pediatric Endocrinology Training Centre) and PETCA - Lagos. In the Netherlands the portal has been visited by students/fellows during pilot courses testing and evaluating the applicability of the portal.

\section{Evaluation of assessment}

A. "Elearning live: interactive gateway to the ESPE e-learning portal" during the second ISPAD Postgraduate Course and Meeting Contemporary 
Diabetes 24-25 April 2013 in Varna, Bulgaria, organized by Prof Violeta Iotova.

A total of 26 participants (fellows pediatric endocrinology, PhD students $(\mathrm{n}=12)$, senior pediatric endocrinologists $(n=14)$ were given entrance to a closed site (course) of the ESPE-e-learning web portal 2 weeks prior to the workshop. The course consisted of the assignment to study a large chapter on growth and growth regulation and to answer multiple-choice questions solving two cases relating to growth disorders.

The fellows and junior pediatric endocrinologists spent in average $98 \mathrm{~min}$ (range 19 - $218 \mathrm{~min}$ ), whereas senior participants spent 119 min (range 23 - $223 \mathrm{~min}$ ). 4 users (2 fellows and 2 senior pediatric endocrinologists) were taken out of study due to lack of time spend ( $<10$ minutes online in the portal).

17 participants answered questions from a case ("Joyce, a girl with intrauterine growth retardation"). The responses to $11 \mathrm{MC}$ questions are given in figure 4.

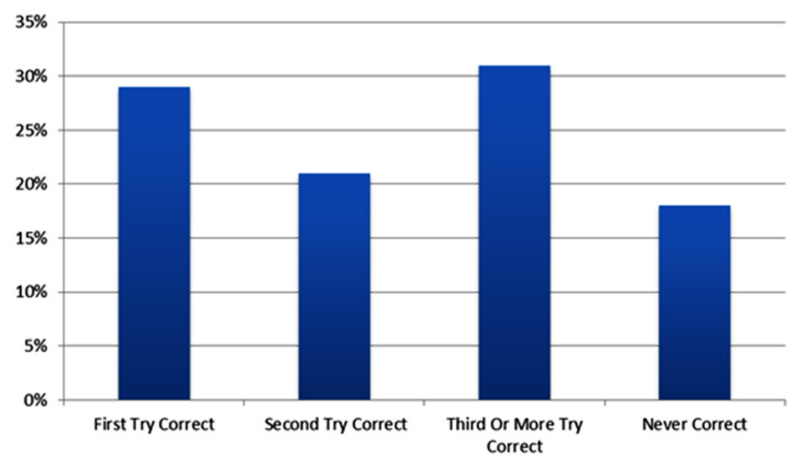

Fig. 4. The average number of tries a user needed to give the correct answer to 11 questions of the case "Joyce, a girl with intrauterine growth retardation" is given. Results represent the average of all 11 questions.

14 participants replied to questions from case 2, "Rebecca" and 9 completed the case. During the workshop an additional case was discussed in class by the senior teacher and subsequently the participants were given the opportunity to discuss and solve one more case on their own pace using their own laptop (fig. 5).

B. "Workshop on laying the foundation for future cooperation in the field of DSD in Bulgaria", Jan-

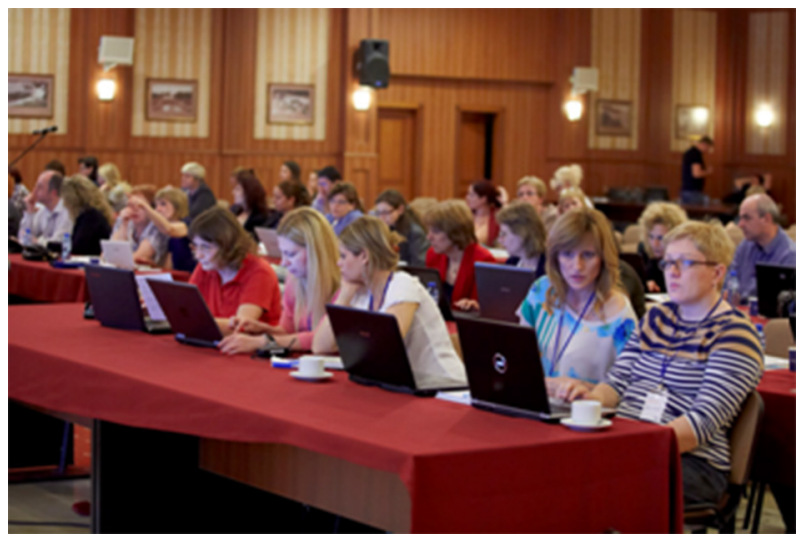

Fig. 5. Participants of the workshop were given the opportunity to solve a case on their own pace using their own laptop while discussing with colleague participants.

uary 23-25,2014, in Varna, Bulgaria, organized by professor Violeta Iotova.

A total of 22 participants (fellows pediatric endocrinology, $\mathrm{PhD}$ students, fellow genetics $(\mathrm{n}=9)$; senior pediatric endocrinologists, other seniors $(\mathrm{n}=$ 13) were given entrance to a closed site (course) of the ESPE e-learning webportal 2 weeks prior to the workshop. The course consisted of the assignment to study 13 chapters describing pathophysiology and multidisciplinary management of newborns, children and adolescents with DSD. In addition, participants were invited to answer multiple-choice questions solving a DSD case "A newborn with ambiguous genitalia". During the workshop two problem solving cases were presented classically: the participants were invited to reply to MC questions using voting pads (Turning Point, Turning technologies LLC, USA, 2002-2011). The responses shown immediately were subject to formative comments of the teacher and discussion among the participants.

Five participants did not study the material (3 fellows/students and 2 seniors). The other 17 participants spent on the average 135 min (range $12-466$ min) studying the chapters and the case. Fellows/junior spent $207 \mathrm{~min}$ (range 27 - $466 \mathrm{~min}$ ), whereas senior participants spent $96 \mathrm{~min}$ (range 12 - $300 \mathrm{~min}$ ).

Seven of 23 participants enrolled in the case "A newborn with ambiguous genitalia", and 6/7 users finished the case. This case consisted of 17 questions. The responses to the $17 \mathrm{MC}$ questions are given in fig 6. 


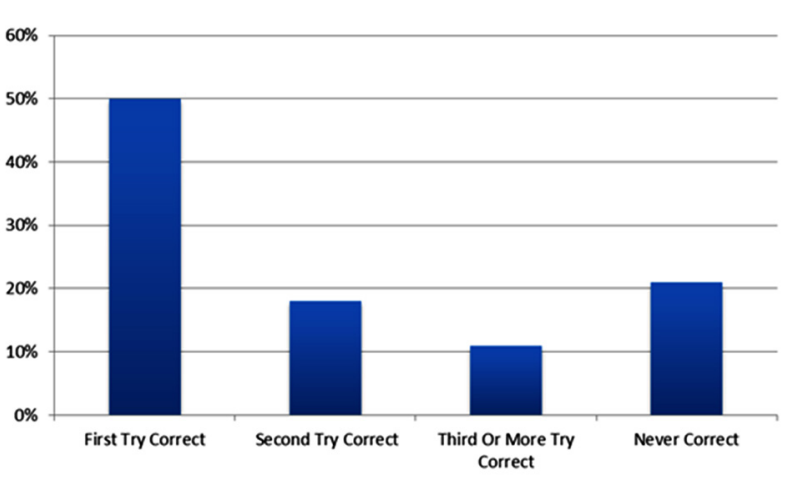

Fig. 6. The average number of tries a user needed to give the correct answer to 17 questions of the case "A newborn with ambiguous genitalia". Results represent the average of 17 questions.

\section{Conclusions and recommendations}

Since the establishment of a robust educational framework of the portal $(2,4)$ the ESPE e-learning portal is being visited not only by ESPE members in Europe but also by many professionals of all continents. In order to reach the aims of the portal i.e. supporting the learning of cognitive objectives, competencies and skills at the core level aiming at medical students and at an advanced level aiming at fellow or postdoctoral students, first of all further extension of content is required covering the broad scope of pediatric endocrinology. Particularly the topic Diabetes
Mellitus is highly relevant and deserves further and extensive coverage.

At the same time the availability of the portal for members and non-members of ESPE needs to be emphasized and made public widely, particularly as the system is being adapted allowing the full use of the portal on iPads, androids, smart phones, etc.

Moreover, relevant feedback from users should be translated by the editorial board to make practical improvements.

It is of specific interest to note that the objectives of e-learning, e-consultation and e-information share considerable overlap:

The aim of e-learning is to provide a certain standard of state of the art knowledge and attitudes towards patient care and management for target groups of students, residents, fellows/postdocs.

The objective of e-consultation is to provide forums for structured expert opinions for clinicians and specialists. Before seeking expert advice, it is prudent to access up-to-date knowledge and current practice. Experts may provide important practical knowledge based on case examples.

The target group of e-information is patients, parents and families. It is critically important that relevant knowledge is shared with each target group in styles and tones that are fully appropriate (6).

Table 2a. Number of visits, average and total visit time in 10 countries visiting the portal most frequently during the period September through December 2013

\begin{tabular}{l|c|c|c|}
\hline \multirow{2}{*}{ Country } & Visits & Average Visit Duration & Total visit time \\
\cline { 2 - 4 } & $\mathrm{N}$ & min & min \\
Netherlands & 470 & 14 & 6863 \\
Australia & 65 & 5 & 316 \\
Brazil & 55 & 6 & 356 \\
United Kingdom & 55 & 6 & 312 \\
Italy & 51 & 6 & 339 \\
Spain & 49 & 8 & 383 \\
India & 39 & 10 & 383 \\
Kenya & 35 & 25 & 877 \\
Nigeria & 33 & 26 & 866 \\
Total (All country's) & 1264 & 12 & 15173 \\
\hline \hline
\end{tabular}


Table 2b. Number of visits, average and total visit time in 10 countries visiting the portal most frequently during the period January through March 2014

\begin{tabular}{l|c|c|c|}
\hline \multirow{2}{*}{ Country } & Visits & Average Visit Duration & Total visit time \\
\cline { 2 - 4 } & $\mathrm{N}$ & min & min \\
Netherlands & 1859 & 37 & 69103 \\
Bulgaria & 185 & 27 & 5029 \\
United Kingdom & 39 & 5 & 207 \\
United States & 30 & 3 & 98 \\
Brazil & 29 & 35 & 1004 \\
Belgium & 28 & 27 & 768 \\
Germany & 21 & 6 & 126 \\
Pakistan & 18 & 7 & 130 \\
Georgia & 14 & 20 & 276 \\
Total (all countries) & 2393 & 33 & 77693 \\
\hline \hline
\end{tabular}

An important and relevant additional aim of the portal is to reach out to "educationally underprivileged" areas in the world as nowadays traditional geographic boundaries are completely bypassed by using the internet. It is encouraging that participants of the Paediatric Endocrine Training Centre West Africa (PETCWA) in Lagos, Nigeria have found the way to the portal. The technical requirements of the portal make it relatively easy to add slides. Thus in order to augment the applicability of the module for countries with limited resources commentary could be added.

The portal intends to facilitate the combination of online learning and face-to-face instruction: blended learning (7). The two courses held in Varna demonstrate that blended learning may bring together the clinicians' daily practice of high-quality interactions between colleagues with clinical theory, cases, extra exercises, and immediate feedback on multiple choice questions. Therefore, the ESPE e-learning portal is not meant to be a stand-alone learning environment; it incorporates the blended learning model and should thus be imbedded in the daily practice.

It should be noted that the participation rate and the time spend in preparation of the workshop varies greatly. It has been shown for medical students that the degree of usage depends primarily on the perceived relevance of the training by e-learning for a summative (fail/pass) examination (8). However, fellows, postdocs and junior/senior staff are in principal well-motivated and for them the formative assessment format (providing immediate feedback) of the e-learning modules are well-suited. Still, the question remains whether incentives to study prior to a workshop should be provided such as a certain study time, number of questions answered, etc.

Specifically for the target group fellow/postdoc a relevant feature of the portal is the integration of learning, instruction and assessment. In addition to being a 'Medical Expert', the competencies of 'Communicator' and 'Collaborator' are crucial. In small scale pilot studies it was demonstrated that the portal's introduction of online, high-quality interaction between experts and clinicians was highly valued by the users (5). Thus, the next step in extending the impact of the e-learning portal is the further development of learning and competency assessment tools. Furthermore, in demonstrating its applicability at a global level, regional and cultural aspects should be fully recognized.

Maximizing the use of the ESPE e-learning portal, users can communicate their thoughts directly to a facilitator; this allows self-directed learning to fuse with the social networking capabilities of the portal. 
In addition the ESPS e-learning portal allows to construct courses consisting of only parts of the various modules with option of feedback by teachers as well as to construct tests (exams) with summative assessment.

\section{Acknowledgements}

We gratefully acknowledge the excellent contributions of Mrs. Conny de Vugt, content manager and MrSander Spaans, webmaster (HealtheSolutions, the Netherlands).

\section{REFERENCES}

1. Grijpink-van den Biggelaar K, Drop SL, Schuwirth L. Development of an e-learning portal for pediatric endocrinology: educational considerations. Horm Res Paediatr. 2010;73:223-30.

2. Henning J, Dewal G, Quenzer M. ILIAS, Die open source Lernplatform. Handbuch für Nutzer, Dozenten und Administratoren. Berlin, uni-edition; 2009.

3. http://www.ilias.de/docu

4. Oeffner F, Schäfer C, Fritz B, Fuchs AL, Rauschendorf A, König R, Kunz J. Interactive e-learning courses in human genetics: usage and evaluation by science and medical students at the faculty of medicin. GMS Z Med Ausbild. 2011;28(3):Doc38.

5. Kranenburg-van Koppen L.J.C. , Kalinka Grijpinkvan den Biggelaar K, Drop SL. An interactive ELearning Portal in Pediatric Endocrinology: Practical Experience. Pharmacy 2013; 1:160-171.

6. Muscarella M, Kranenburg-van Koppen L, Grijpink-van den Biggelaar K, Drop SL. Global application of disorders of sex development-related electronic resources: e-learning, e-consultation and einformation sharing. Endocr Dev. 2014;27:268-83.

7. Sleator RD. The evolution of eLearning background, blends and blackboard.... Sci Prog. 2010;93(3):319-34.

8. Hörnlein A, Mandel A, Ifland M, Lüneberg E, Deckert J, Puppe F. Acceptance of medical training cases as supplement to lectures. GMS Z Med Ausbild. 2011;28(3):Doc42 